The second application deals with an old case of infection, and the existence of syphilis seems to be used only to support the application for financial benefit. It touches the problem of spreading venereal diseases by demobilized soldiersa problem which is still as important as it was when it first became known, at the beginning of the sixteenth century.

For permission to publish this paper we are indebted to Mr. R. H. Adcock, Clerk of the Lancashire County Council, and to Dr. F. Hall, County Medical Officer of Health.

\title{
REFERENCES
}

France, R. Sharpe (1939) Trans. Hist. Soc., Lancs. and Cheshire, 90, 11. Rolleston, J. D. (1943) Brit. J. vener. Dis., 19, 169.

\section{GENITAL OEDEMA IN RELATION TO FILARIASIS IN THE GOLD COAST}

Between June and September 1944 there were 875 African soldiers admitted to the 37th General Hospital at Accra in the Gold Coast. Of these there were 10 who showed genital oedema in which filariasis was suspected. The oedema affected the penis in all of these patients and the scrotum also in 7 of them. On each an examination was made for microfilariae, by means of a day-and-night blood film to detect blood-borne varieties, and of the taking of a small skin scraping from the inner aspect of the thigh to detect the lymphatic-borne embryos of Onchocerca volvulus. In addition a blood count was done for the detection of eosinophilia.

Parasites were demonstrated in 7 of the patients, of whom 5 showed the microfilariae of Loa loa in the blood and one had microfilariae of Acanthocheilonema perstans; in another the existence of onchocerciasis was proved by the skin scraping.

\section{Loa loa}

Of the 5 cases with Loa loa infection, 3 had had attacks of genital oedema during the past 3 years, and all denied-probably falsely-recent sexual intercourse. One was undergoing arsenical treatment for syphilis, but none had active venereal disease at the time of examination. All the patients had swelling of the penis. Two had also gross scrotal oedema, the scrotum reaching the size of a grape-fruit in each case, and in another there was a hydrocele. In all these cases the skin scrapings gave negative results, but in 3 of them an eosinophilia between 15 and 20 per cent was found.

Treatment was by means of a suspensory bandage, and in 4 cases the attack subsided within a week and the men were discharged from hospital. In the case of the fifth patient, who had both penile and scrotal oedema, the surgeons performed an operation, removing the elephantoid skin of the penis and scrotum, transplanting the testicles into the thighs, and restoring the appearance of the penis by a skin graft. The immediate results of this procedure were very satisfactory.

\section{Microfilariae perstans (Acanthoceilonema perstans)}

The man infected with microfilariae of $A$. perstans had very well marked oedema of both penis and scrotum and, although the patient denied sexual intercourse during the previous 4 months, there was an associated acute gonococcal urethritis. There was no eosinophilia and nothing abnormal was seen in the skin scraping, but the microfilariae perstans were readily demonstrated in the blood. The patient did not give any history of a previous attack, but, in view of the severity of this 
one, the oedema of which caused a recurrent spontaneous paraphimosis, the patient was " boarded" out of the army.

\section{Onchocerca volvulus}

The patient with onchocerciasis had obvious oedema of the penis and scrotum, but the eosinophil count was only 2 per cent. No microfilariae were seen in the blood, but the skin scraping revealed their presence. No subcutaneous swellings indicating the site of the adult worm were observed and no microfilariae could be found in the eyes. There had been one previous attack of genital oedema 2 years previously, which had lasted for 3 months. The present swelling, however, improved greatly after one week and the patient was then discharged to duty. An added interest in this case was a discharging nodule in the scrotum in which Guinea-worm larvae were demonstrated microscopically.

\section{REVIEWS OF BOOKS}

The Management of Neurosyphilis. By Bernhard Dattner, M.D., Jur.D., with the collaboration of Evan W. Thomas, M.D., and Gertrude Wexler, M.D. Foreword by J. E. Moore, M.D. 398 pp. Wm. Heinemann Ltd., London, Grune and Stratton, New York, 1944. Price 25s.

This book, dedicated to the memory of Wagner-Jauregg, whose assistant the author was in Vienna, is the product of many years' experience of the treatment of neurosyphilis both in Europe and, since 1938, in New York. The volume is divided into two parts : the first part deals with the technique of withdrawal and examination of spinal fluid, its interpretation and evaluation ; the second part is devoted to the various methods of treatment in vogue, their application and results.

The author leaves no doubt as to the necessity for and the value of a lumbar puncture. In his conclusion, "the real step forward", he writes, "has been the experience derived from the study of the changes in the spinal fluid in successfully treated paretics, and the understanding of the decisive importance of the humoral syndrome within the framework of diagnostic and therapeutic effort". The need for a complete examination of the cerebrospinal fluid is stressed ; the mere report of a Wassermann reaction without a cell count, protein content estimation and colloidal curve, is not only useless but apt to be very misleading. The employment of the fine Dattner needle has made the operation of lumbar puncture a minor procedure, possible in the out-patient department.

A wealth of clinical material is recorded, but it is a matter for regret that, in view of the author's great experience, there is not more information about the clinical aspects of general paralysis, its incidence, its pathogenesis and its pathology ; no doubt the title of the book precludes these wider aspects. In Great Britain it would appear that general paralysis is a fast-disappearing disease ; it would be interesting to know the position in other countries.

In the section on malaria, no mention is made of Plasmodium ovale, which has been employed extensively in Great Britain. Admittedly it is a difficult strain of malaria to maintain, although its benign course, with an almost invariably spontaneous recovery, has made treatment availablc. for the more debilitated type of patient. The malaria charts reproduced are disappointing, especially Chart 1 , in which the fever is almost remittent, in my experience to be regarded as a danger signal. I have always laid particular stress on the need for observing the true intermittent character of the fever. Malaria therapy is not an easy procedure, and in the Wagner-Jauregg clinic the mortality rate was undoubtedly very low ; a more detailed account of the nursing and management of a case of malaria might well be included. At the Horton Centre rough parasite counts ate carried out daily ; this procedure has contributed very largely to reducing the mortality risk to negligible figures. In Vienna and New York it appears that all cases are bloodinoculated. Whereas in Great Britain the majority of cases are probably infected with malaria by means of blood supplied from the Horton Centre, the importance of maintaining a mosquitoinfected strain is not generally recognized. By this means one is certain of preserving a pure strain, and the original Madagascar strain of $P$. vivax remains clinically and parasitologically the same now as it was when first employed twenty years ago.

A full account of other fever-producing agents is given, although many have now fallen into disrepute. The pros and cons of malaria plus arsenotherapy and malaria versus artificial pyrexia are fully discussed, and the authors are to be congratulated on presenting an unbiassed picture and keeping an open mind. To quote Dattner: "There is no reason why one should stress 